\title{
Correction to: What is the Prevalence of Hip Intra-Articular Pathologies and Osteoarthritis in Active Athletes with Hip and Groin Pain Compared with Those Without? A Systematic Review and Meta-Analysis
}

Joshua J. Heerey ${ }^{1}$ (D) Joanne L. Kemp ${ }^{1}$ - Andrea B. Mosler ${ }^{1}$. Denise M. Jones ${ }^{1} \cdot$ Tania Pizzari $^{1} \cdot$ Mark J. Scholes $^{1}$. Rintje Agricola ${ }^{2} \cdot$ Kay M. Crossley ${ }^{1}$

Published online: 23 April 2019

(c) Springer Nature Switzerland AG 2019

\section{Correction to: Sports Medicine} https://doi.org/10.1007/s40279-019-01092-y

Section 3.7: The Fig. 2 and its caption which previously read:

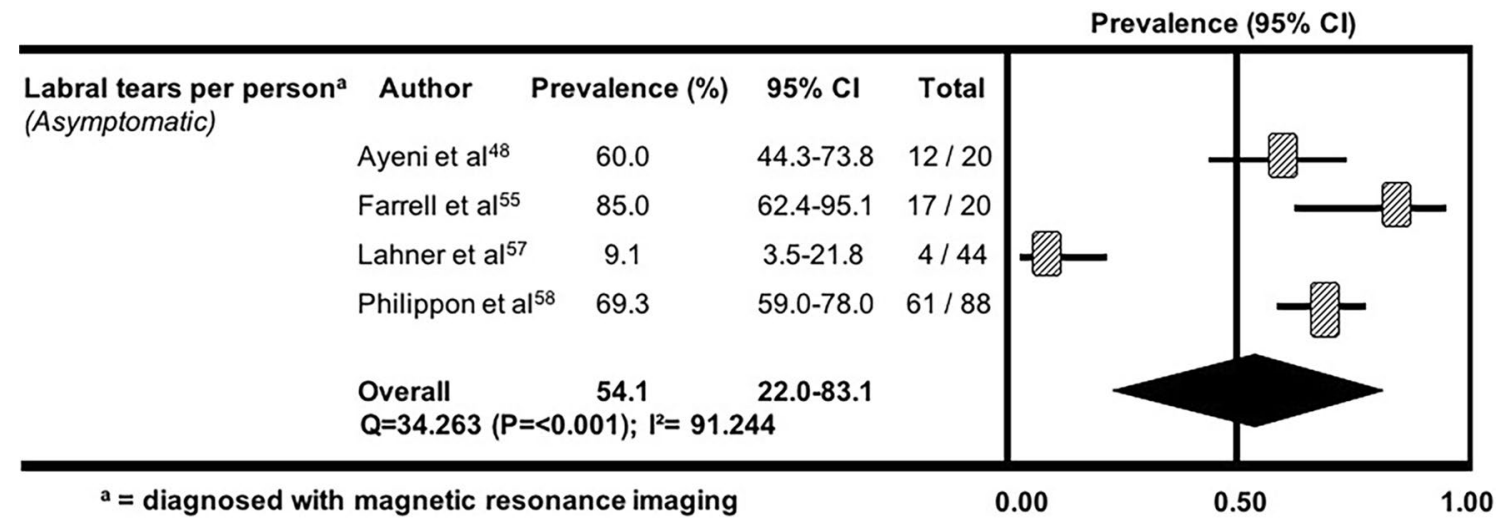

Fig. 2 Prevalence and 95\% confidence interval (CI) of labral tears per person in asymptomatic athletes

The original article can be found online at https://doi.org/10.1007/ s40279-019-01092-y.

Kay M. Crossley

k.crossley@1atrobe.edu.au

1 La Trobe Sport and Exercise Medicine Research Centre, School of Allied Health, College of Science, Health and Engineering, La Trobe University, Bundoora, VIC 3068, Australia

2 Department of Orthopaedics, Erasmus University Medical Center, Rotterdam, The Netherlands 
Should read as:

Prevalence $(95 \% \mathrm{Cl})$

\begin{tabular}{|c|c|c|c|c|c|}
\hline \multirow{5}{*}{$\begin{array}{l}\text { Labral tears per hip } \\
\text { (Symptomatic) }\end{array}$} & Author & Prevalence (\%) & $95 \% \mathrm{Cl}$ & Total & \\
\hline & Dickenson et $a^{67}$ & 20.0 & $6.6-47.0$ & $3 / 15$ & \\
\hline & Mayes et al ${ }^{65}$ & 20.0 & $8.6-40.0$ & $5 / 25$ & \\
\hline & Overall & 20.0 & $10.3-35.2$ & & \\
\hline & \multicolumn{4}{|c|}{$Q=0.00(P=1.00) ; I^{2}=0.00$} & \\
\hline \multirow{4}{*}{$\begin{array}{l}\text { Labral tears per hip } \\
\text { (Asymptomatic) }\end{array}$} & Author & Prevalence (\%) & $95 \% \mathrm{Cl}$ & Total & \multirow{4}{*}{$-O$} \\
\hline & Dickenson et al ${ }^{67}$ & 23.2 & $15.8-32.7$ & $22 / 95$ & \\
\hline & Mayes et $a^{65}$ & 44.9 & $35.7-54.4$ & $48 / 107$ & \\
\hline & $\begin{array}{l}\text { Overall } \\
Q=10.766(P=<0.0\end{array}$ & $\begin{array}{c}33.4 \\
.001) ; l^{2}=90.171\end{array}$ & $15.9-57.0$ & & \\
\hline
\end{tabular}

Fig. 2 Prevalence and 95\% confidence interval (CI) of labral tears per hip in symptomatic and asymptomatic athletes

Section 3.7: The Fig. 3 and its caption which previously read:

Prevalence $(95 \% \mathrm{Cl})$

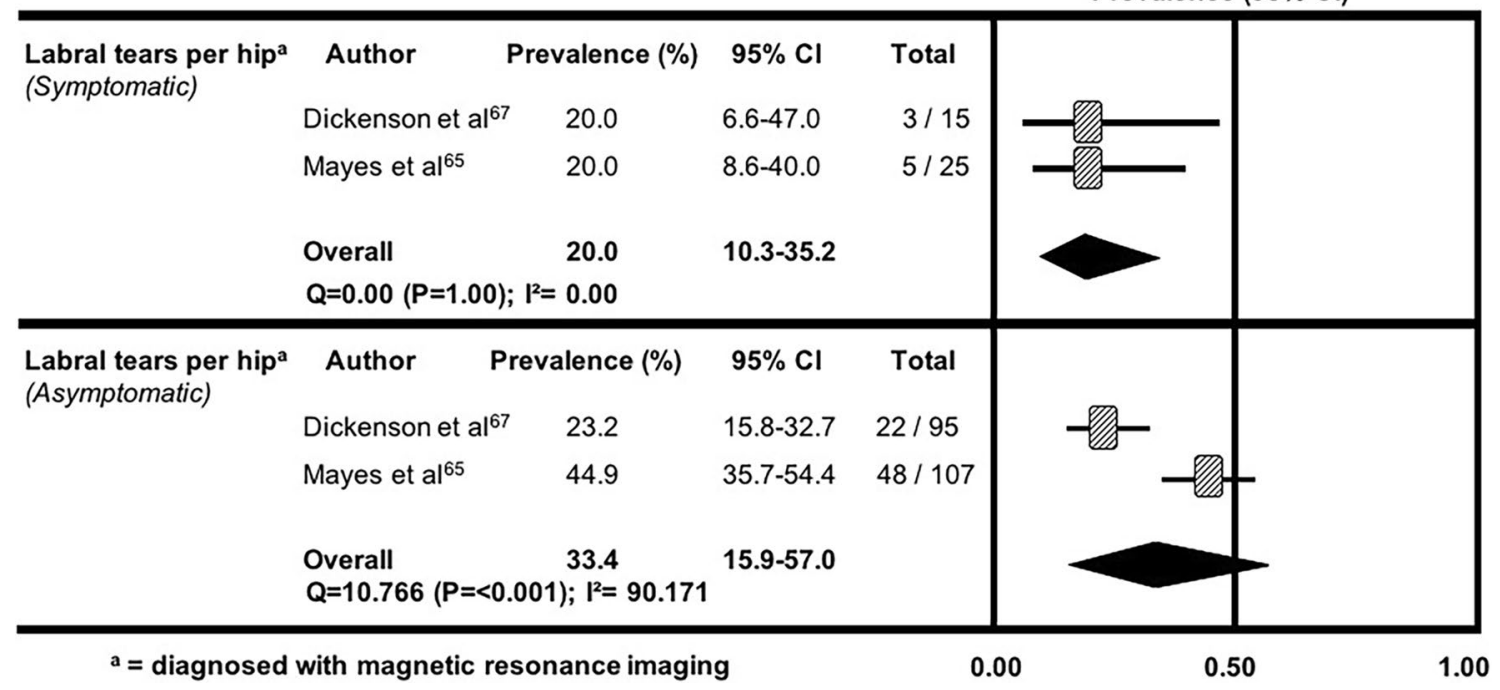

Fig. 3 Prevalence and 95\% confidence interval (CI) of labral tears per hip in symptomatic and asymptomatic athletes 
Should read as:

Prevalence $(95 \% \mathrm{Cl})$

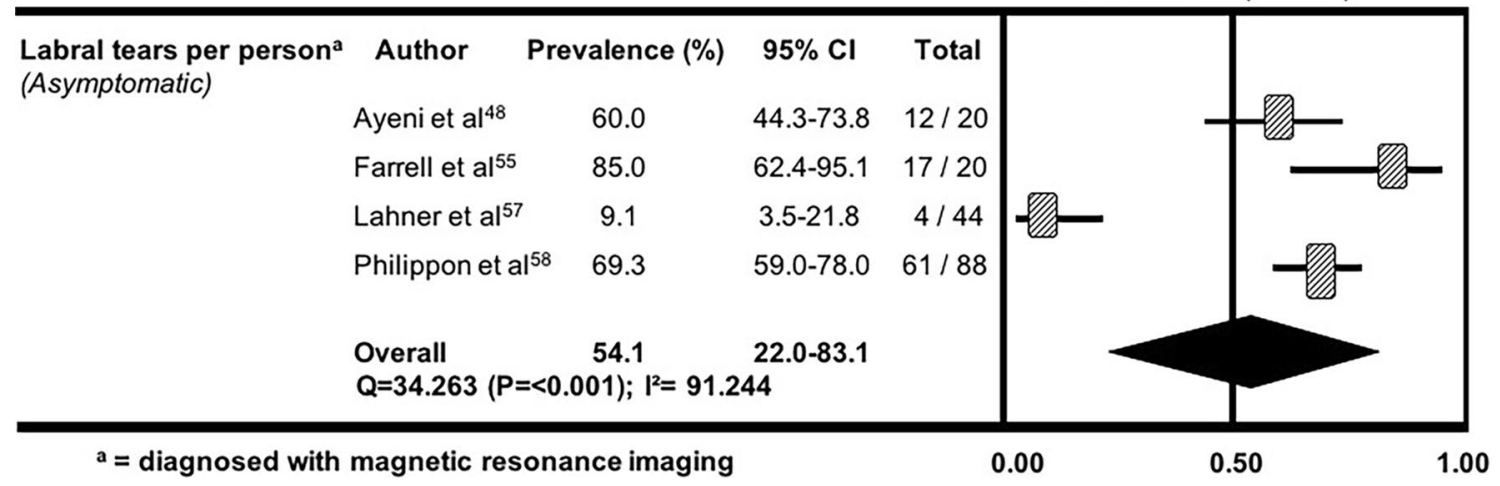

Fig. 3 Prevalence and 95\% confidence interval (CI) of labral tears per person in asymptomatic athletes

Section 3.7: Figure 4 caption which previously read:

Fig. 4 Prevalence and 95\% confidence interval (CI) of labral tears per person in asymptomatic athletes in cutting, impingement and asymmetrical sports

Should read as:

Fig. 4 Prevalence and 95\% confidence interval (CI) of labral tears per person and per hip in asymptomatic athletes in cutting, impingement and asymmetrical sports

The original article has been corrected. 